\title{
The Effect of Glycyrrhetinic Acid on Pharmacokinetics of Cortisone and Its Metabolite Cortisol in Rats
}

\author{
Dan Lin, ${ }^{1}$ Wei Sun, ${ }^{2,3}$ Zhe Wang, ${ }^{3}$ Lian-Guo Chen, ${ }^{3}$ Xiao-Le Chen, ${ }^{3}$ Shuang-Hu Wang, ${ }^{3}$ \\ Wan-Shu Li, ${ }^{3}$ Ren-Shan Ge, ${ }^{2}$ and Guo-Xin $\mathrm{Hu}^{3,4}$ \\ ${ }^{1}$ Analytical and Testing Center, Wenzhou Medical College, Wenzhou 325035, China \\ ${ }^{2}$ The 2nd Affiliated Hospital Wenzhou Medical College, Wenzhou 325027, China \\ ${ }^{3}$ School of Pharmacy, Wenzhou Medical College, Wenzhou 325035, China \\ ${ }^{4}$ Teaching Center of Medical Functional Experiment, Wenzhou Medical College, Wenzhou 325035, China
}

Correspondence should be addressed to Guo-Xin Hu, wzhhgx@yahoo.com.cn

Received 2 July 2012; Revised 1 October 2012; Accepted 2 October 2012

Academic Editor: James D. Murray

Copyright $\odot 2012$ Dan Lin et al. This is an open access article distributed under the Creative Commons Attribution License, which permits unrestricted use, distribution, and reproduction in any medium, provided the original work is properly cited.

The purpose of this paper is to study pharmacokinetics of cortisone (E) and its metabolite cortisol (F) in rats after administration of glycyrrhetinic acid (GA) and cortisone. Healthy male SD rats were randomized to be given $20 \mathrm{mg} / \mathrm{kg}$ E or E combined with $10 \mathrm{mg} / \mathrm{kg}$ GA. Blood samples were collected at 5, 10, 20, 40, 60, 90, 120, 150, 180, and $240 \mathrm{~min}$ after administration. The serum concentrations of $\mathrm{E}$ and $\mathrm{F}$ were determined by HLPC and pharmacokinetic parameters were calculated using DASver2.0 software. The parameters of $\mathrm{AUC}_{(0-t)}, \mathrm{AUC}_{(0-\infty)}$, and $C_{\max }$ for $\mathrm{E}$ in the group of $\mathrm{E}+\mathrm{GA}$ were significantly higher than those in the group of $\mathrm{E}(P<0.01)$; the half-time $\left(t_{1 / 2 \beta}\right)$ was extended compared to $\mathrm{E}(P<0.05)$ and $\mathrm{CL} / \mathrm{F}$ was dropped obviously $(P<0.01)$. The rise in $\mathrm{AUC}_{(0-t)}, \mathrm{AUC}_{(0-\infty)}$, and $C_{\max }$ for cortisol in the group of $\mathrm{E}+\mathrm{GA}$ was significantly compared to the group of $\mathrm{E}(P<0.01)$. CL/F was lower than $\mathrm{E}(P<0.01)$ and the half-time $\left(t_{1 / 2 \beta}\right)$ was slightly extended. In this study, we find that GA restrains the metabolism of $\mathrm{E}$ and $\mathrm{F}$ and thus increases AUC, $t_{1 / 2 \beta}$, and $C_{\max }$ of $\mathrm{E}$ and $\mathrm{F}$, which may be related to its inhibition effect on $11 \beta$-hydroxysteroid dehydrogenase (11 $\beta$-HSD).

\section{Introduction}

Licorice is one of the most commonly used clinical drugs [1]. When glycyrrhizin is administered orally, glycyrrhetinic acid is the major metabolite [2]. Glycyrrhetinic acid (GA) is an important bioactive substance of licorice with a variety of pharmacological effects, such as anti-inflammatory [3], antivirus [4], antiulcer [5], and adrenal cortical hormone kind function [6]. Clinical trials clearly show that glycyrrhetinic acid has a good effect on all types of dermatitis [7], purulent scar disease [8], and hair follicle infection and can cure gingivitis, esophagus inflammatory disease. It plays a physiological function in reducing lipemia and antiatherosclerotic and preventing atherosclerosis $[9,10]$. Many enzymes are inhibited by glycyrrhetinic acid in corticosteroids metabolic process, such as $17 \beta$-HSD, $11 \beta$ HSD, $5 \alpha$-reductase, and $5 \beta$-reductase [11-13].

Two distinct isozymes of $11 \beta$-HSD catalyze the interconversion of hormonally active cortisol (F) and inactive cortisone (E), which are important human glucocorticoids [14-16]. This occurs via inhibition of the enzyme by inhibiting the enzyme 11- $\beta$-hydroxysteroid dehydrogenase. Glucocorticoids have anti-inflammatory, immunosuppressive, antishock, and other pharmacological roles, with clinically important applications [17].

We develop a high performance liquid chromatography method for the simultaneous determination of cortisone and cortisol in rat serum. The pharmacokinetics of cortisone and cortisol in rats after the administration of glycyrrhetinic acid and cortisone were studied.

\section{Experimental}

2.1. Chemicals, Reagents, and Stock Solutions. Cortisone (lot no. 0001447641, purity $>98.0 \%$ ) and trifluoroacetic acid (TFA) (lot no. 064K3647, purity $>98.0 \%$ ) were purchased from Sigma-Aldrich Company (St. Louis, MO, USA). 
Cortisol and pirfenidone (both purity $>98.0 \%$ ) were gifts from Rockefeller University (New York, USA). All other chemicals were analytical grade and used without further purification. Purified water was prepared in house with a Milli-Q water system from Millipore (Bedford, MA, USA).

The drugs were accurately weighed $( \pm 0.0001 \mathrm{~g})$, on an analytical balance from METTLER TOLEDO AB204-A (Zurich, Switzerland), to prepare stock solutions of individual compounds at a concentration of $1 \mathrm{mg} / \mathrm{mL}$ in methanol. All of the standard solutions were stored in the dark at $277 \mathrm{~K}$ for a maximum of one month. Working solutions for calibration and controls were prepared from the stock solution by dilution using methanol. The internal standard (IS) working solution $(100 \mu \mathrm{g} / \mathrm{mL})$ was prepared by diluting its stock solution with methanol. Calibration curves were prepared using blank serum spiked at concentrations of $50,100,250,500,1000,2000,4000$, and $6000 \mathrm{ng} / \mathrm{mL}$. Low, medium, and high quality control (QC) samples at concentrations of 100,1000 , and $4000 \mathrm{ng} / \mathrm{mL}$ were prepared in the same way as the calibration standard.

\subsection{Equipment and Conditions. HPLC system (Agilent 1100)} was equipped with quaternary pump, on-line vacuum degasser, autosampler, column compartment, diode array detector, and Agilent Chem Station Rev A.10.02. Chromatographic separation was achieved on a $4.6 \times 150 \mathrm{~mm}, 5 \mu \mathrm{m}$ particle and an Agilent Zorbax SB-C18 column was kept constant during on the run: a source of temperature of $298 \mathrm{~K}$ using a one-step linear gradient. Mobile phases A (acetonitrile), B (0.1\% TFA), and $\mathrm{C}$ (water) ratio changed as follows: $0 \sim 12 \mathrm{~min}, 24 \sim 34 \% \mathrm{~A}, 40 \% \mathrm{~B}$, and $36 \sim 26 \% \mathrm{C}$. The detector operated at $246 \mathrm{~nm}$ for cortisone and cortisol. The injection volume was $20.0 \mu \mathrm{L}$, and the flow rate of mobile phase was $0.9 \mathrm{~mL} / \mathrm{min}$.

\subsection{Calibration Standards and Quality Control Samples.} Stock solutions of cortisone $(1 \mathrm{mg} / \mathrm{mL})$, cortisol $(1 \mathrm{mg} / \mathrm{mL})$, and IS $(1 \mathrm{mg} / \mathrm{mL})$ were separately prepared in $25 \mathrm{~mL}$ volumetric flasks with methanol and stored at $277 \mathrm{~K}$. Working solutions for calibration and controls were prepared from the stock solution by dilution using methanol. The IS working solution $(100 \mu \mathrm{g} / \mathrm{mL})$ was prepared by diluting its stock solution with methanol. Calibration curves were prepared using blank serum spiked at concentrations of 50, 100, 250, 500, 1000, 2000, 4000, and $6000 \mathrm{ng} / \mathrm{mL}$. Low, medium, and high quality control (QC) samples at concentrations of 100 , 1000 , and $4000 \mathrm{ng} / \mathrm{mL}$ were prepared in the same way as the calibration standard.

2.4. Animals and Treatment. Male SD rats, weighing $300 \pm$ $20 \mathrm{~g}$ (Certificate no. 2007-0005) were purchased from ShangHai SLAC Laboratory animal Co., ltd. Rats were divided into 2 groups, each group was administered with glycyrrhetinic acid $10 \mathrm{mg} / \mathrm{kg}$ or vehicle (DMSO versus water = $1: 9(\mathrm{~V} / \mathrm{V}))$ three times at 0,12 , and $24 \mathrm{~h}$ via intraperitoneal injection. Rats were anesthetized by $10 \%$ chloral hydrate before intraperitoneal injection of cortisone $20 \mathrm{mg} / \mathrm{kg}$. Blood samples $800 \mu \mathrm{L}$ were directly collected into a clean tube from the tail vein at $5,10,20,40,60,90,120,150,180$, and $240 \mathrm{~min}$. After centrifugation at $5000 \mathrm{rpm}$ for $10 \mathrm{~min}$, serum was separated and stored at $253 \mathrm{~K}$ until analysis.

2.5. Sample Preparation. The serum samples were prepared using, liquid-liquid extraction technique. A $300 \mu \mathrm{L}$ aliquot of the serum sample was taken in a $10 \mathrm{~mL}$ glass test tube, and on that $20 \mu \mathrm{L}$ of IS $(100 \mu \mathrm{g} / \mathrm{mL})$ was spiked and $150 \mu \mathrm{L}$ of sodium hydroxide solution $(0.01 \mathrm{moL} / \mathrm{L})$ was added. To this, $3 \mathrm{~mL}$ of extraction solvent (ethyl acetate) was added and vortex mixed on a multiple vortexer for $2.0 \mathrm{~min}$, followed by centrifugation at $4000 \mathrm{rpm}$ for $15 \mathrm{~min}$. The supernatant was dried under nitrogen and dissolved in $200 \mu \mathrm{L}$ of mobile phase. A $20 \mu \mathrm{L}$ aliquot of the final supernatant was injected into the HPLC system for analysis.

2.6. Method Validation. The analytical method was validated to demonstrate the selectivity, recovery, accuracy, and precision of measurements.

Selectivity was established by the lack of interference peaks at the retention time for cortisone, cortisol, and IS.

Recovery of the method was determined at three concentration levels $(100,1000$, and $4000 \mathrm{ng} / \mathrm{mL})$ by comparing the peak area obtained from the extracted serum samples with the peak area obtained by the direct injection of the corresponding concentration spiked standard solution in the extracted blank serum.

QC samples at three concentration levels $(100,1000$, and $4000 \mathrm{ng} / \mathrm{mL}$ ) were analyzed to assess the accuracy and precision of the method. Intraday accuracy and precision $(n=6)$ were evaluated by assays of QC samples at different times during the same day. Interday accuracy and precision were tested from the results of replicate assays of QC samples over three consecutive days. Accuracy of the method was estimated based on relative error (RE) and precision was estimated by the relative standard deviation (RSD).

2.7. Statistical Analysis. Data were expressed as $\bar{x} \pm s$. The significance of differences was assessed by unpaired $t$-test and one-way analysis of variance.

\section{Results}

3.1. Method Validation. In our study, the resolution of cortisone, cortisol, and their internal standard was satisfactory. No interference from internal materials in serum can be observed in the HPLC chromatograms. The retention time of cortisone, cortisol, and internal standard was $10.1 \mathrm{~min}, 9.3 \mathrm{~min}$, and $7.6 \mathrm{~min}$, respectively. The HPLC chromatograms are shown in Figure 1.

The regression equation of cortisone was $Y_{1}=0.1991$ $X_{1}+0.0041(r=0.9998)$ and its lower limit of quantitation (LLOQ) was $0.05 \mathrm{mg} / \mathrm{L}(n=6$; $\mathrm{RSD}=3.70 \%)$; the regression equation of cortisol was $Y_{2}=0.2262 X_{2}-0.0033(r=$ $0.9999)$ and its LLOQ was $0.05 \mathrm{mg} / \mathrm{L}(n=6$; RSD $=$ $5.22 \%)$. The extractive recoveries for cortisone were $(82.00 \pm$ $0.64) \%$, $(79.68 \pm 2.04) \%$, and $(81.21 \pm 0.98) \%$, respectively at different serum standard concentrations of $0.1,1.0$, and 


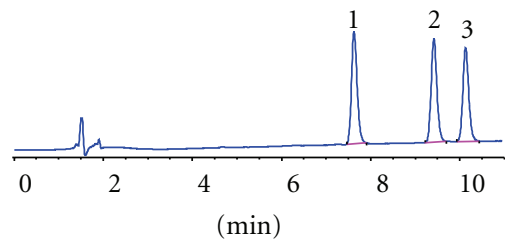

(a)

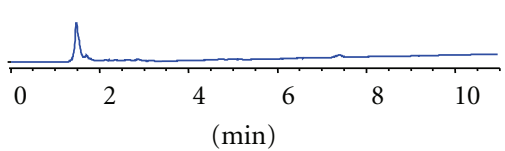

(b)

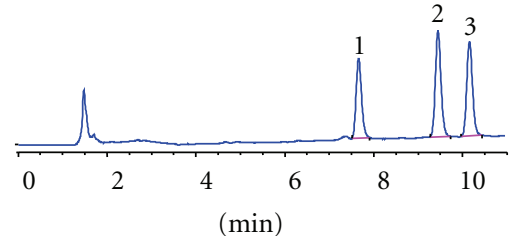

(c)

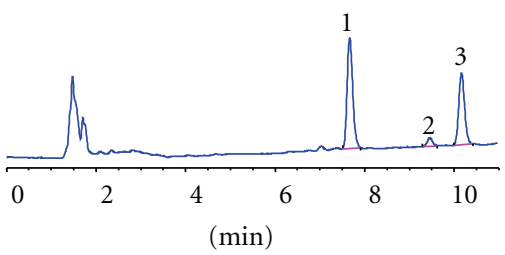

(d)

Figure 1: HPLC chromatograms of cortisone and cortisol. (a) Pure standard substance, (b) blank serum, (c) serum spiked with cortisone, cortisol, and internal standard and (d) sample; 1: internal standard, 2: cortisol and 3: cortisone.

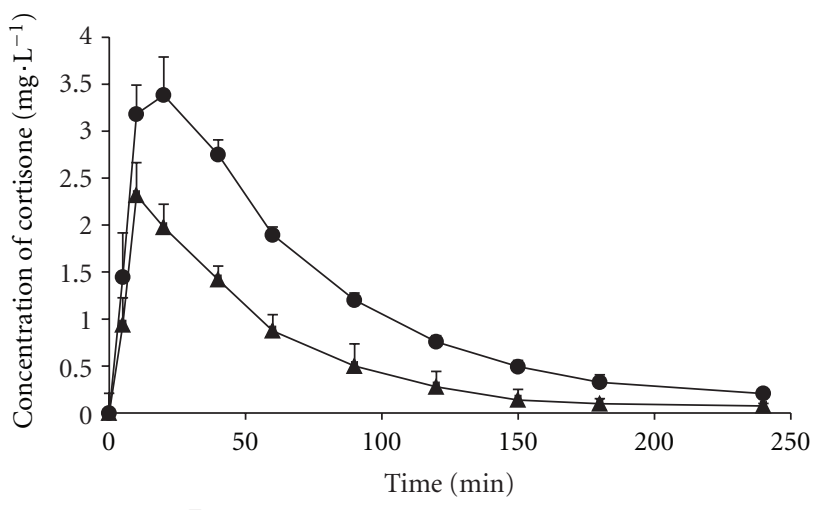

$\longrightarrow \mathrm{E}$
$\rightarrow \mathrm{E}+\mathrm{GA}$

Figure 2: Mean concentration-time curve of cortisone in two groups $n=6$.

$4.0 \mathrm{mg} / \mathrm{L}$; the extractive recoveries for cortisol at the same concentration levels were $(78.18 \pm 1.63) \%,(79.71 \pm 1.02) \%$, and $(81.47 \pm 1.18) \%$, respectively. The intra- and interday precision (RSD) of cortisone was $4.53 \%, 2.34 \%$, and $3.29 \%$ and $4.87 \%, 2.76 \%$, and $3.79 \%$ at different serum standard concentrations of $0.1,1.0$, and $4.0 \mathrm{mg} / \mathrm{L}$; the intra- and interday precision (RSD) of cortisol at the same concentration levels were $4.97 \%, 3.74 \%$, and $2.67 \%$ and $4.95 \%, 3.56 \%$, and $2.36 \%$.

3.2. Pharmacokinetic Study of Cortisone and Cortisol. To investigate the pharmacokinetic parameters, we applied compartmental model. The mean concentration-time curves of cortisone in two groups were presented at Figure 2 and the pharmacokinetic parameters were presented at Table 1. The mean concentration-time curves of cortisol in two groups were presented in Figure 3 and the pharmacokinetic parameters were presented in Table 2.
TABLE 1: The main pharmacokinetic parameters of cortisone in two groups $n=6$.

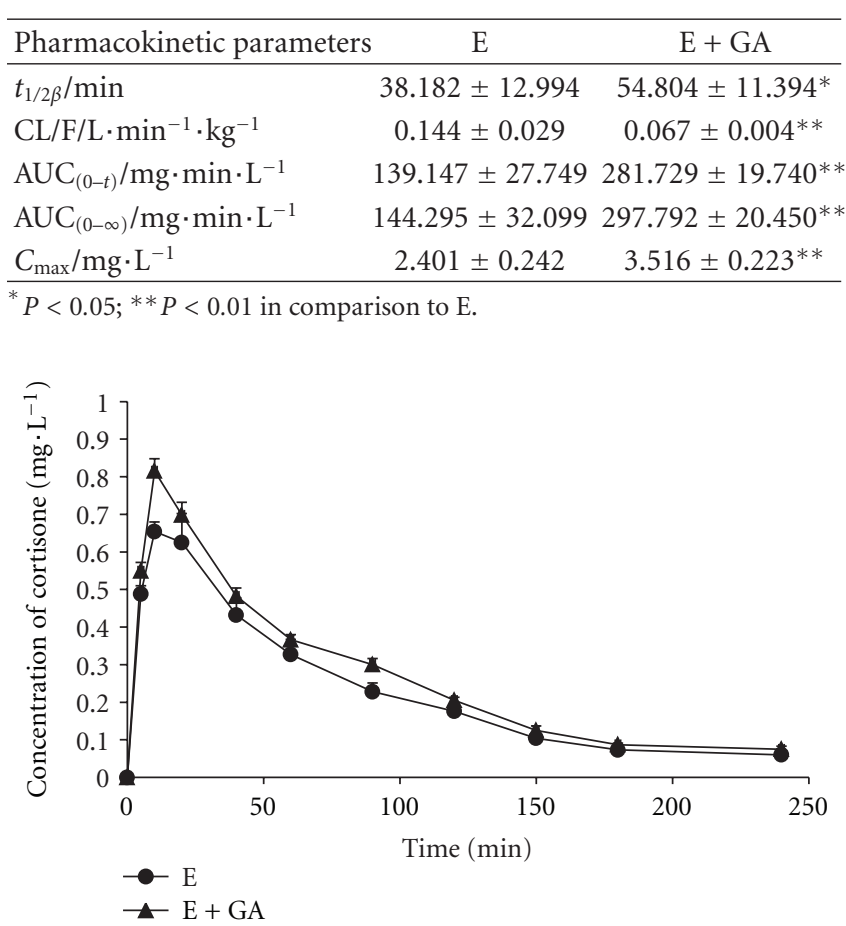

Figure 3: Mean concentration-time curve of cortisol in two groups $n=6$.

\section{Discussion}

We studied the pharmacokinetic characteristics of $\mathrm{E}$ and $\mathrm{F}$ in rats combined using GA and $\mathrm{E}$ and then fitting their pharmacokinetic parameters. A two-compartment model was found meeting concentration-time curves of cortisone and cortisol in group $\mathrm{E}$ and $\mathrm{E}+\mathrm{GA} . T_{1 / 2}, \mathrm{CL} / \mathrm{F}, \mathrm{AUC}_{(0-t)}$, $\mathrm{AUC}_{(0-\infty)}$, and $C_{\max }$ of cortisone and cortisol were affected 
TABLE 2: The main pharmacokinetic parameters of cortisol in two groups $n=6$.

\begin{tabular}{|c|c|c|}
\hline Pharmacokinetic parameters & E & $\mathrm{E}+\mathrm{GA}$ \\
\hline$t_{1 / 2 \beta} / \mathrm{min}$ & $60.859 \pm 4.065$ & $62.557 \pm 5.415$ \\
\hline $\mathrm{CL} / \mathrm{F} / \mathrm{L} \cdot \mathrm{min}^{-1} \cdot \mathrm{kg}^{-1}$ & $0.343 \pm 0.012$ & $0.284 \pm 0.011^{* *}$ \\
\hline $\mathrm{AUC}_{(0-t)} / \mathrm{mg} \cdot \mathrm{min} \cdot \mathrm{L}^{-1}$ & $53.054 \pm 2.102$ & $64.416 \pm 2.776^{* *}$ \\
\hline $\mathrm{AUC}_{(0-\infty)} / \mathrm{mg} \cdot \min \cdot \mathrm{L}^{-1}$ & $58.411 \pm 2.038$ & $70.576 \pm 2.656^{* *}$ \\
\hline$C_{\max } / \mathrm{mg} \cdot \mathrm{L}^{-1}$ & $0.627 \pm 0.04$ & $0.815 \pm 0.033^{* *}$ \\
\hline
\end{tabular}

by glycyrrhetinic acid. The $t_{1 / 2}$ of cortisone in group $\mathrm{E}+$ GA is $43 \%$ more as much as group E. AUC increased by $110 \%$, and $C_{\max }$ by $50 \%$, almost to $3.516 \mathrm{mg} / \mathrm{L}$, but CL/F was significantly decreased. AUC of cortisol in group E + GA increased almost $25 \%, C_{\max }$ increased by $30 \%$, to $0.815 \mathrm{mg} / \mathrm{L}$; however, CL/F was significantly decreased. Although $t_{1 / 2}$ of both extended, no significant differences were found. Because individual differences exist in animal test, and the sample size is too small to achieve requirement of test power (power $=1-\beta$ ), as the result differences in parent population cannot be found out.

GA is an inhibitor of $11 \beta$-HSD that catalyzes conversion between $\mathrm{E}$ and $\mathrm{F}$, so the change of pharmacokinetic characteristics of $\mathrm{E}$ and $\mathrm{F}$ may be the result of affect of GA $[16,18]$. Two isoforms of $11 \beta$-HSD have been cloned $[19,20]$, with type I ( $11 \beta$-HSD1) as a primary reductase that converts $\mathrm{E}$ to $\mathrm{F}$, and type II (11 $\beta$-HSD2) as a unidirectional oxidase that converts $\mathrm{F}$ back to $\mathrm{E}$. The effects of GA on both enzymes have been reported. Our previous research demonstrated that GA significantly increased endogenous corticosterone level and further increased its level when administrated in combination with GA [17]. In human subjects, liquorice has also been found to inhibit $11 \beta$-dehydrogenase, as measured by a rise in the plasma half-life of F [21]. In our study, we clearly demonstrated that GA increased the AUC of E after combinatory administration, indicating that GA inhibited $11 \beta$-HSD1, which is a primary reductase located in the liver and metabolizes $\mathrm{E}$ into $\mathrm{F}$. However, we also witnessed the rise of $\mathrm{F}$ level, suggesting that GA may inhibit the further metabolism of $\mathrm{F}$.

As we all know that GA can increase effective blood concentration and $t_{1 / 2}$ of glucocorticoids, when combined using that it can increase the effect of anti-inflammatory, antiallergic action, antistress response, and so on [22]. It also can inhibit the hypothalamic-pituitary-adrenal-acceptor systems, decreasing and relieving some reverse effect, withdrawal symptom, and dependency, so it is often used as replacement drugs when reduce or withdraw cortical hormone $[23,24]$.

The result found at present study indicated that the pharmacokinetic characteristics of $\mathrm{E}$ and its metabolite can be changed by combined preparation of GA and E. It has significant clinical value. The wide use of GA can greatly increase compliance, but the administrate dose of GA should be noticed when using GA combined with $\mathrm{E}$ or acted as the alternative medicines.
Although radioimmunity is used to detect glucocorticoids usually for its high sensitivity; the result would be much higher than the actual concentration $[18,19]$. Because target molecule, glucocorticoids, would cross-react with their isomers or metabolites [25]. Previous research had proved the result that conducted by ELISA and RIA assay it would have the same problem [26]. In this work, we employed an HPLC-DAD assay to detect $\mathrm{E}$ and $\mathrm{F}$ concentrations in serum. Compared to the methods mentioned above, the specificity of HPLC-DAD is much higher, so the result is much more reliable.

\section{Authors' Contribution}

Dan Lin and Wei Sun contributed equally to this work.

\section{Conflict of Interests}

None of the authors has any other conflict of interests related to this paper.

\section{Acknowledgment}

This paper was partially supported by the Natural Science Foundation of Zhejiang province (LY12H31002) and NSFC (81102092).

\section{References}

[1] S. Shibata, "A drug over the millennia: pharmacognosy, chemistry, and pharmacology of licorice," Yakugaku Zasshi, vol. 120, no. 10 , pp. 849-862, 2000.

[2] S. Nafisi, F. Manouchehri, and M. Bonsaii, "Study on the interaction of glycyrrhizin and glycyrrhetinic acid with RNA," Journal of Photochemistry and Photobiology B, vol. 4, no. 111, pp. 27-34, 2012.

[3] Z. Gao, X. Kang, and C. Xu, "Research progress of anticancer mechanism of glycyrrhetinic acid," Zhongguo Zhong Yao Za Zhi, vol. 36, no. 22, pp. 3213-3216, 2011.

[4] J. Wang, Q. Sun, P. Gao, J. F. Wang, C. Xu, and Q. L. Sun, "Bioconversion of glycyrrhizinic acid in liquorice into 18-betaglycyrrhetinic acid by Aspergillus parasiticus speare BGB.," Prikladnaia Biokhimiia i Mikrobiologiia, vol. 46, no. 4, pp. 462466, 2010.

[5] S. Yano, M. Harada, K. Watanabe et al., "Antiulcer activities of glycyrrhetinic acid derivatives in experimental gastric lesion models," Chemical and Pharmaceutical Bulletin, vol. 37, no. 9, pp. 2500-2504, 1989.

[6] G. Mazzocchi, G. P. Rossi, G. Neri, L. K. Malendowicz, G. Albertin, and G. G. Nussdorfer, " $11 \beta$-Hydroxysteroid dehydrogenase expression and activity in the human adrenal cortex," FASEB Journal, vol. 12, no. 14, pp. 1533-1539, 1998.

[7] M. Saeedi, K. Morteza-Semnani, and M. R. Ghoreishi, "The treatment of atopic dermatitis with licorice gel," Journal of Dermatological Treatment, vol. 14, no. 3, pp. 153-157, 2003.

[8] X. L. Li, A. G. Zhou, L. Zhang, and W. J. Chen, "Antioxidant status and immune activity of glycyrrhizin in allergic rhinitis mice," International Journal of Molecular Sciences, vol. 12, no. 2, pp. 905-916, 2011.

[9] J. W. Tomlinson, E. A. Walker, I. J. Bujalska et al., "11 $1 \beta$-Hydroxysteroid dehydrogenase type 1: a tissue-specific regulator 
of glucocorticoid response," Endocrine Reviews, vol. 25, no. 5, pp. 831-866, 2004.

[10] Y. L. Chang, C. L. Chen, C. L. Kuo, B. C. Chen, and J. S. You, "Glycyrrhetinic acid inhibits ICAM-1 expression via blocking JNK and NF-B pathways in TNF- $\alpha$-activated endothelial cells," Acta Pharmacologica Sinica, vol. 31, no. 5, pp. 546-553, 2010.

[11] D. Deluca, A. Krazeisen, R. Breitling, C. Prehn, G. Möller, and J. Adamski, "Inhibition of 17beta-hydroxysteroid dehydrogenases by phytoestrogens: comparison with other steroid metabolizing enzymes," Journal of Steroid Biochemistry and Molecular Biology, vol. 93, no. 2-5, pp. 285-292, 2005.

[12] R. C. Andrews, O. Rooyackers, and B. R. Walker, "Effects of the $11 \beta$-hydroxysteroid dehydrogenase inhibitor carbenoxolone on insulin sensitivity in men with type 2 diabetes," Journal of Clinical Endocrinology and Metabolism, vol. 88, no. 1, pp. 285291, 2003.

[13] S. A. Latif, T. J. Conca, and D. J. Morris, "The effects of the licoricw derivative, glycyrrhetinic acid, on hepatic $3 \alpha$ - and $3 \beta$-hydroxysteroid dehydrogenases and $5 \alpha$ - and $5 \beta$-reductase pathways of metabolism of aldesterone in male rats," Steroids, vol. 55, no. 2, pp. 52-58, 1990.

[14] J. S. Raul, V. Cirimele, B. Ludes, and P. Kintz, "Detection of physiological concentrations of cortisol and cortisone in human hair," Clinical Biochemistry, vol. 37, no. 12, pp. 11051111, 2004.

[15] F. K. Głowka, K. Kosicka, and M. Karaźniewicz-Łada, "HPLC method for determination of fluorescence derivatives of cortisol, cortisone and their tetrahydro- and allo-tetrahydrometabolites in biological fluids," Journal of Chromatography B, vol. 878, no. 3-4, pp. 283-289, 2010.

[16] G. X. Hu, H. Lin, C. M. Sottas, D. J. Morris, M. P. Hardy, and R. S. Ge, "Inhibition of $11 \beta$-hydroxysteroid dehydrogenase enzymatic activities by glycyrrhetinic acid in vivo supports direct glucocorticoid-mediated suppression of steroidogenesis in leydig cells," Journal of Andrology, vol. 29, no. 3, pp. 345351, 2008.

[17] S. Matsui, H. Matsumoto, Y. Sonoda et al., "Glycyrrhizin and related compounds down-regulate production of inflammatory chemokines IL- 8 and eotaxin 1 in a human lung fibroblast cell line," International Immunopharmacology, vol. 4, no. 13, pp. 1633-1644, 2004.

[18] D. Armanini, G. Bonanni, M. J. Mattarello, C. Fiore, P. Sartorato, and M. Palermo, "Licorice consumption and serum testosterone in healthy man," Experimental and Clinical Endocrinology and Diabetes, vol. 111, no. 6, pp. 341-343, 2003.

[19] A. K. Agarwal, C. Monder, B. Eckstein, and P. C. White, "Cloning and expression of rat cDNA encoding corticosteroid $11 \beta$-dehydrogenase," Journal of Biological Chemistry, vol. 264, no. 32, pp. 18939-18943, 1989.

[20] A. K. Agarwal, T. Mune, C. Monder, and P. C. White, "NAD+dependent isoform of $11 \beta$-hydroxysteroid dehydrogenase. Cloning and characterization of cDNA from sheep kidney," Journal of Biological Chemistry, vol. 269, no. 42, pp. 25959 25962, 1994.

[21] P. M. Stewart, A. M. Wallace, S. M. Atherden, C. H. Shearing, and C. R. W. Edwards, "Mineralocorticoid activity of carbenoxolone: contrasting effects of carbenoxolone and liquorice on $11 \beta$-hydroxysteroid dehydrogenase activity in man," Clinical Science, vol. 78, no. 1, pp. 49-54, 1990.

[22] S. Shibata, "Chemistry and cancer preventing activities of ginseng saponins and some related triterpenoid compounds," Journal of Korean medical science, vol. 16, pp. S28-S37, 2001.

[23] K. Shiratori, S. Watanabe, and T. Takeuchi, "Effect of licorice extract (Fm100) on release of secretin and exocrine pancreatic secretion in humans," Pancreas, vol. 1, no. 6, pp. 483-487, 1986.

[24] S. Farese, A. Kruse, A. Pasch et al., "Glycyrrhetinic acid food supplementation lowers serum potassium concentration in chronic hemodialysis patients," Kidney International, vol. 76, no. 8, pp. 877-884, 2009.

[25] M. Baeck, L. Marot, J. F. Nicolas, C. Pilette, D. Tennstedt, and A. Goossens, "Allergic hypersensitivity to topical and systemic corticosteroids: a review," Allergy, vol. 64, no. 7, pp. 978-994, 2009.

[26] E. F. De Palo, G. Antonelli, A. Benetazzo, M. Prearo, and R. Gatti, "Human saliva cortisone and cortisol simultaneous analysis using reverse phase HPLC technique," Clinica Chimica Acta, vol. 405, no. 1-2, pp. 60-65, 2009. 

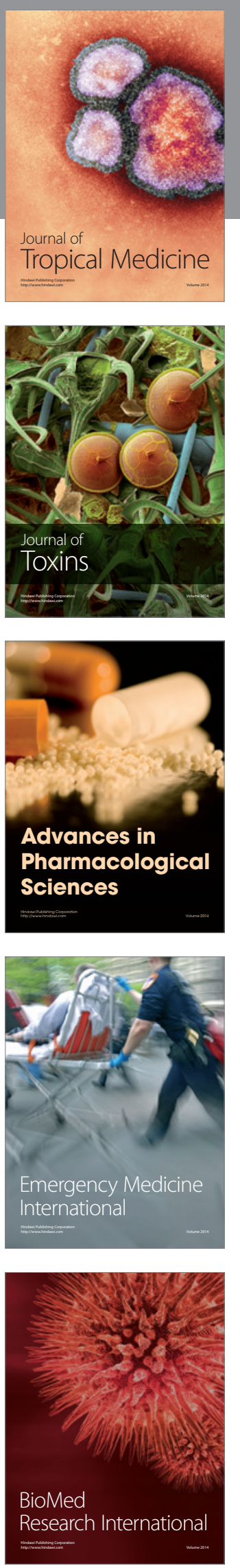
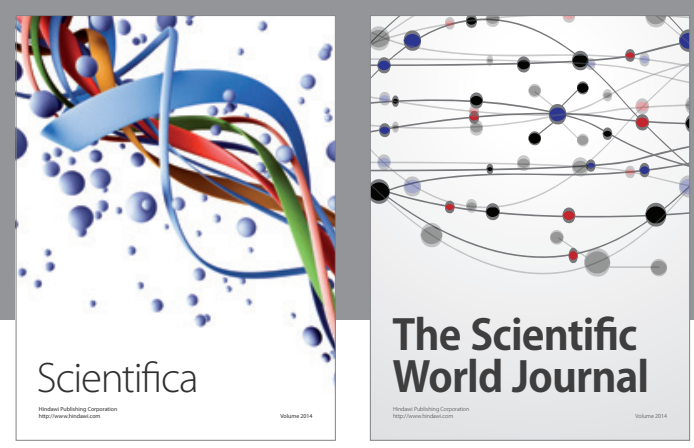

The Scientific World Journal
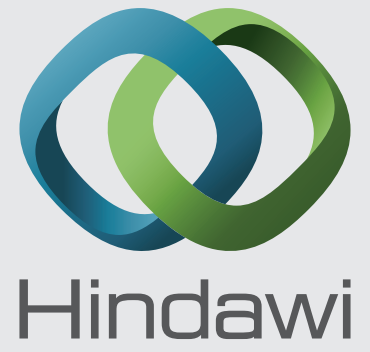

Submit your manuscripts at

http://www.hindawi.com
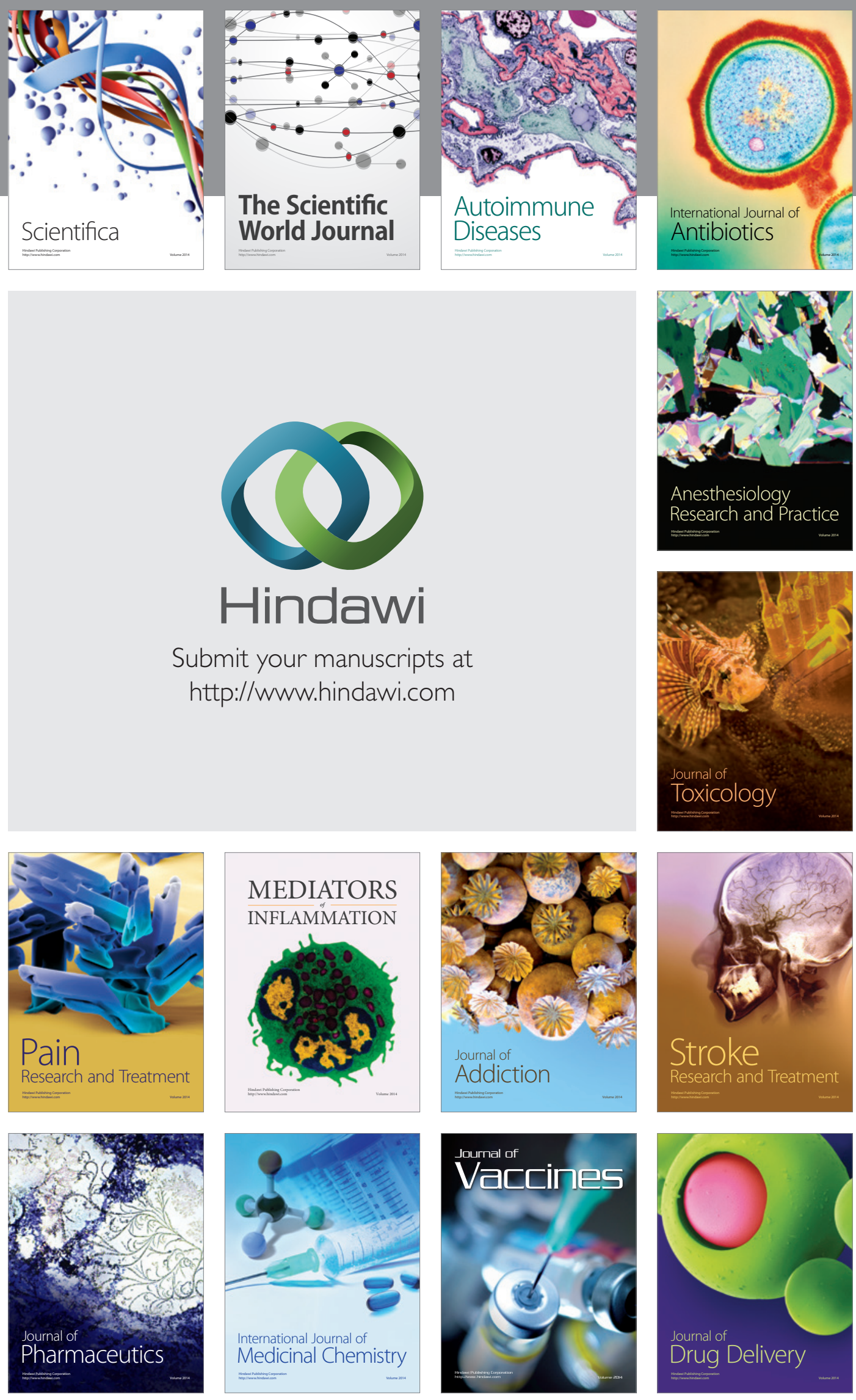